\title{
Do Patients Correctly Use Steroid Nose Spray? A Patient-Reported Survey of the Nasal Spray Technique and Patient Compliance
}

Waqas Jamil ${ }^{1}$, Abdullah Alahwal ${ }^{1}$, Ravinder Suman ${ }^{1}$, Megan Whitwell ${ }^{1}$, Farah Naz ${ }^{2}$, Thomas Beech

1. ${ }^{1}$ Queen Elizabeth Hospital UK, ENT department.

${ }^{2}$ Dow University of Health and Sciences, Karachi, Pakistan

*Corresponding Author: Waqas Jamil, ENT department, Queen Elizabeth Hospital UK.

Received date: April 19, 2021: Accepted date: May 22, 2021: Published date: August 28, 2021

Citation: Jamil W, Alahwal A, Suman R, Whitwell M, Naz F, Beech T (2021). Do patients correctly use steroid nose spray? A patient-reported survey of the nasal spray technique and patient compliance; J. of Clinical Otorhi. 3(4). DOI: 10.31579/2692-9562/033

Copyright: ( 2021 , Waqas Jamil. This is an open access article distributed under the Creative Commons Attribution License, which permits unrestricted use, distribution, and reproduction in any medium, provided the original work is properly cited.

\section{Abstract:}

Background: Correct nasal spray technique and patient compliance are the two most important factors in the use of steroid nose spray.

Objectives: To find out if patients use steroid nasal spray with a correct spray technique and if they are compliant in using the spray.

Design: Patient-reported survey

Participants: 100 participants ( 1 excluded)

Main outcome measures 1) Nasal spray technique 2) Patient compliance

Results: Out of 99 participants included in this study only one patient used steroid nose spray with a completely correct spray technique. $40 \%$ of patients received guidance instructions from the prescriber about the spray technique. $70 \%$ of patients reported using their spray regularly and $53 \%$ of patients were found using the correct dosage of the spray.

Conclusions: Wrong spray technique and patient noncompliance is common and can be corrected. This survey emphasizes the importance of giving written and verbal instructions about the use of spray to the patients.

Keywords: nasal sprays; rhinitis; allergic

Key Points:

- $\quad$ Only 1 patient out of 99 , used steroid nasal spray with a completely correct spray technique.

- Nasal spray technique was taught only to $40 \%$ of the patients

- $70 \%$ of the patients reported regular use of the steroid nose spray and $53 \%$ of patients were found to use correct spray dosage.

- Wrong spray technique and non-compliance can be the reason behind the treatment failure with steroid nasal spray.

- We recommend following "British Society for Allergy and Clinical Immunology-how to apply a nasal spray" and/or video instruction from "asthma.org.uk- how to use nasal spray" for the correct spray technique.

\section{Introduction:}

Background: Various studies conducted in the past have proven the efficacy of steroid nasal spray in the treatment of inflammatory nasal conditions. [1],[2] Currently, topical steroid nasal sprays are considered as the first-line treatment for the management of allergic rhinitis (hay fever) and chronic rhinosinusitis.[1],[3],[4],[5] Intranasal steroids work locally inside the nose and are found to be more effective than systemic steroids [2]. Local application of steroids in the nose reduces systemic absorption, hence reducing systemic side effects [6]. Various steroidbased nasal sprays are available i.e. Beconase, Nasonex, Avamys, 
Flixonase [7]. Combination nasal spray is also available which contains topical antihistamine and topical steroid i.e. Dymista [8].

Previous studies have investigated the correlation between the spray technique and the distribution of drug inside the nose [9],[10],[11],[12]. Correct spray technique and patient compliance are the two important factors for the nasal spray to work. Furthermore, incorrect spray technique can be associated with side effects i.e. irritation and epistaxis [6]. Current guidance on the management of chronic rhinosinusitis, allergic and nonallergic rhinitis strongly recommends clinicians to check nasal spray technique and compliance [3], [5].

Significant material is available on the internet to educate people about nasal spray use, however, some of them are inaccurate [7, 13-16]. Therefore, after extensive research, we recommend following the written instructions for the use of steroid nasal spray from "British Society for Allergy and Clinical Immunology" or/and video tutorial from " asthma.org.uk- how to use nasal spray" [7],[13] (See below). We recommend following these steps when using steroid nose spray:

- Clear the nose.

- Slightly bend head forward.

- Use opposite hand when holding spray (Right hand for left nostril and left hand for right nostril).
- $\quad$ Direct spray inside the nose away from nasal septum (towards turbinate) towards ipsilateral ear or eye.

- Administer spray- avoid hard sniffing.

- Repeat the same for the other nostril.

\section{Objectives:}

The main objectives of this survey were:

1) To investigate if patients use a correct spray technique while administering steroid nose spray.

2) To investigate the patient's compliance in using the steroid nose spra

\section{Methods:}

3.1 Study design and Setting: This survey was conducted at Queen Elizabeth Hospital in Birmingham, UK. Initially, a written paper survey form (see figure 1) was distributed among the patients who were using steroid nasal spray and who came to attend rhinology and immunology outpatient clinics. But, shortly after this survey started, face to face patient consultations were stopped due to COVID-19 outbreak. Hence, a telephonic patient-reported survey was undertaken for the remaining patients. During the telephonic survey, we made a minor change in the question 3 of the survey (see figure 1)

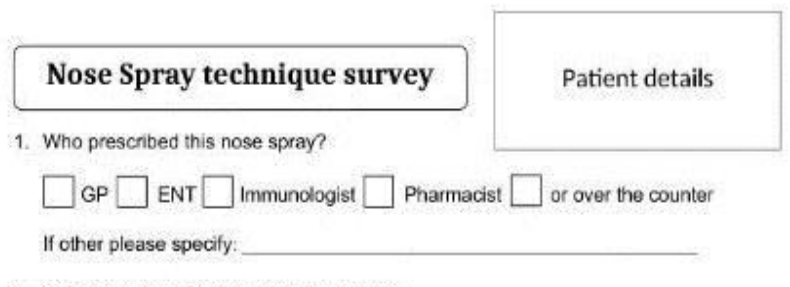

2. Were you shown how to use nose spray?

Yes $\square$ № $\square$ If yes please specify by whiom:

3. Describe your body / head position do you use your nose spray? (tox appuriane)

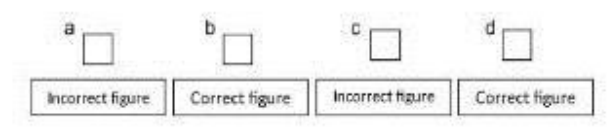

If other please give full details:

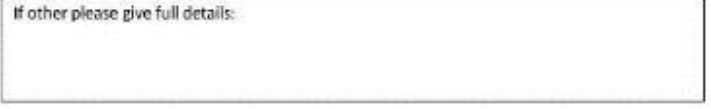

4. In which direction in the nose you squirt your nose spray?

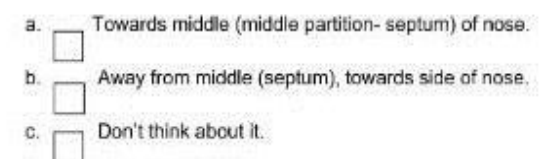

Give full details: 
i.e. patients were asked to describe the head position, as patients can't see head position photos printed on the written survey form. Also, we educated patients about the correct spray technique while collecting answers for the telephonic survey.

3.2 Participants: As this survey was specifically about the use of steroid nose spray, non-steroid formulations were not included i.e. nasal decongestant spray, saline spray etc. Additionally, there is a minor difference in the way the steroid nasal drops are instilled in the nose as compared to the spray technique. This survey only included patients using steroid nose spray (not steroid nasal drops).

3.3 Data sources: Data collection started on 10 February 2020 and completed on 14 August 2020. We have chosen random patients from ENT rhinology and immunology clinics. During Pre-COVID phase of this survey, patients who came to attend clinic were verbally asked if they use steroid nose spray and if they want to be a part of the survey. If the answers to both the questions were "yes" then the survey responses were recorded from those patients. Similarly, during COVID-19 outbreak, patients booked into the clinic who were using steroid nose spray were contacted by phone and if they agreed to be a part of this survey then their responses were recorded.

3.4 Study size: Data was collected from 100 patients.

\section{Results and analysis:}

4.1 Participants: Total100 patients took part in this survey. 15 patients filled in paper survey proforma before COVID-19 outbreak and the remaining 85 responded to the telephonic survey. Mean age of the participated patients in this survey was 49 years old, ranging from 18 to 77 years. There were 53 males and 46 females and the male: female ratio was 1.15:1.

4.2 When analysing the patient's responses, one respondent was using otrovine instead of steroid spray. Hence, we excluded this patient from the study, which dropped the total number of participants included in the study to 99 .

4.2.1 Patient responses: Patient responses to the survey questions are as below:

1. Who prescribed this nose spray?
i. $\quad$ ENT $53 \%$ (53 patients)
ii. GP $42 \%$ (42 patients).
iii. Over the counter $3 \%$ (3 patients).
iv. $1 \%$ (1 patient) cannot remember who prescribed the spray
v. No spray was prescribed by the immunologist.

2. Were you shown how to use nose spray?

i. $\quad 40 \%$ (40 patients) responded yes

ii. $\quad 60 \%$ (59 patients) responded No

Further breakdown of the taught spray technique in those $40 \%$ cases was:

a) $24 \%$ of cases (24 patients) by the ENT team.

b) $15 \%$ of cases (15 patients) by GP.

c) $1 \%$ of cases ( 1 case) by an asthma nurse.

\subsection{Outcome Data:}

4.3.1 Spray technique: Majority of the patients were using steroid nose spray with an incorrect spray technique. Only 1 patient out of 99 used steroid nose spray in a completely correct manner i.e. followed each step correctly. Different steps in using nose spray were all analysed separately i.e. head position, the direction of spray inside the nose, hand preference for holding spray bottle, sniffing, tasting spray in the mouth (See figure 2).

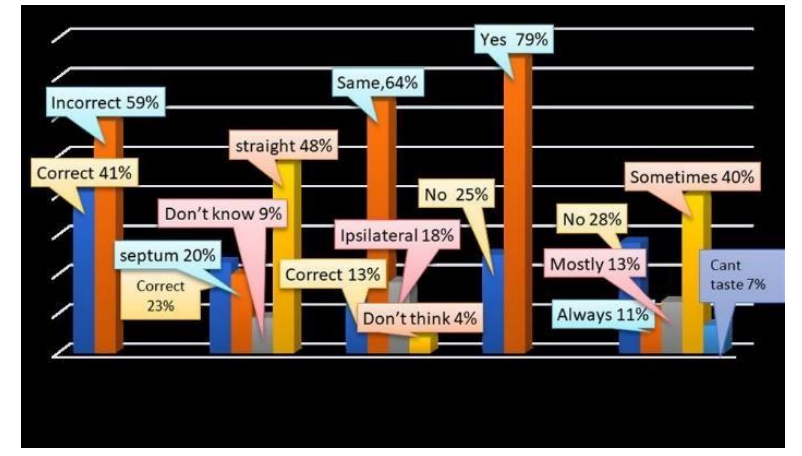

4.3.2 Patient compliance: Compliance issues were also identified in the use of steroid nose spray. Majority of the patients revealed "regular" use of the spray $70 \%$ (69 patients). However, some patients reported using their spray "most of the times" $14 \%$ (14 patients) and "sometimes" $16 \%$ (16 patients) respectively. $53 \%$ of patients were found using correct spray dose but 34\% (34 patients) were using the incorrect dose of the prescribed spray; either underdosing or overdosing. 13\% (13 patients) were unable to recall the spray name, neither we were able to find the spray name in our documentation. Hence, we can not comment whether they used correct spray dosage (See figure 3).
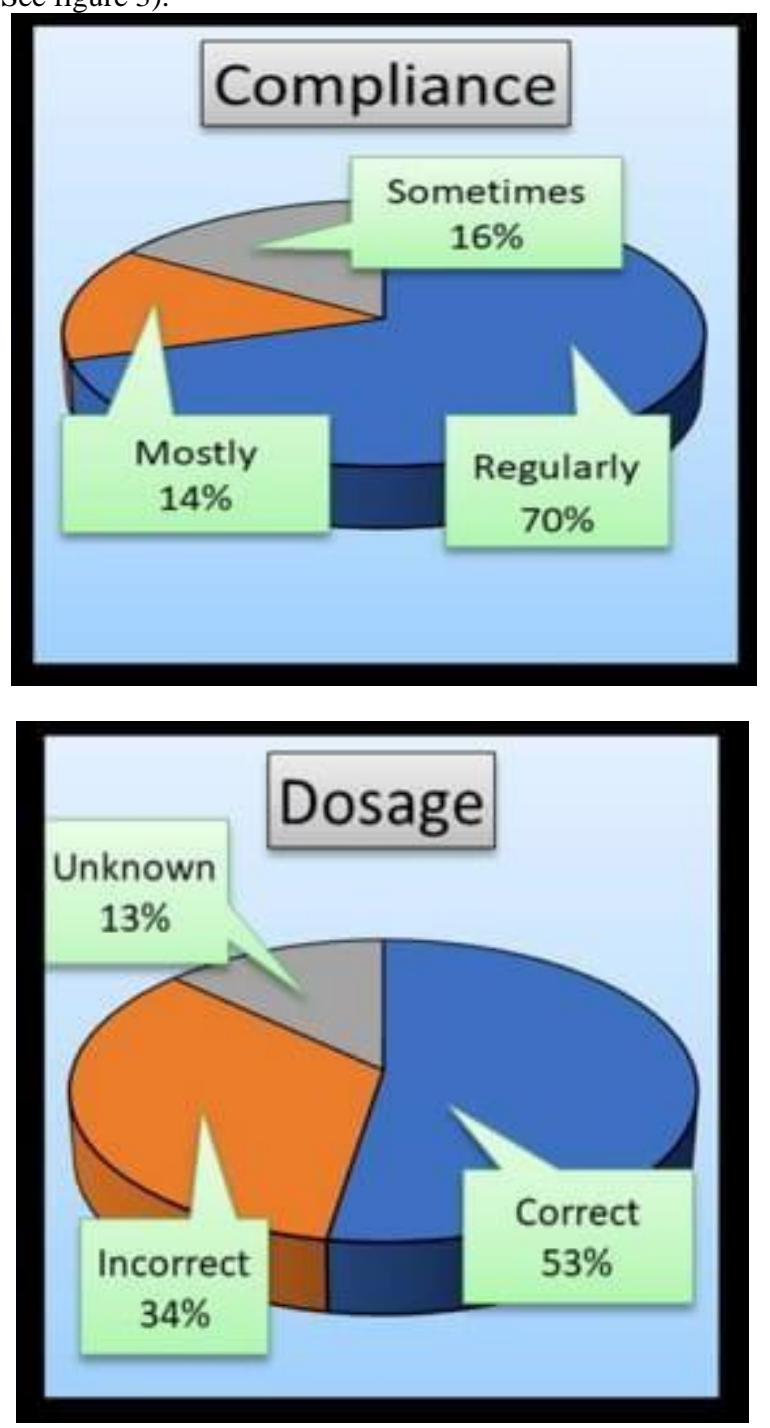
4.3.3 Nasal sprays: Below is the list of nasal sprays and the percentage of patients using these sprays:

- $\quad$ Dymista 33 patients $(34 \%)$

- $\quad$ Nasonex 21 patients $(21 \%)$

- Avamys 23 patients (23\%)

- $\quad$ Flixonase 4 patients (4\%)

- Beconase 4 patients $(4 \%)$

- $\quad$ Budenasoide 1 patient $(1 \%)$

- 13 patients cannot remember the name of the spray (13\%).

\section{Discussion:}

5.1 Summary: To our best knowledge, this is the first patient-reported survey assessing each step of the nasal spray technique and identifying the common mistakes. Out of 99 patients, only 1 patient used the steroid nose spray with a completely correct spray technique. This survey also identified non-compliance in the use of steroid nose spray and using the wrong spray dosage. This is a major finding because we know that the spray technique and correct dosage are the two key factors for the successful medical treatment $[3,5]$. European position paper on chronic rhinosinusitis 2020 and British Society for Allergy and Clinical Immunology 2017 update on the management of Allergic and Non-Allergic rhinitis both emphasizes clinicians to check steroid nasal spray technique and patient compliance especially in cases of failed medical treatment $[3,5]$.

Also, this survey identified that spray technique was taught in only $40 \%$ of cases when it should have been taught to every patient [3, 5]. To complicate things further, some of the material available on the internet for the patients about the spray technique is not reliable and doubtfull [15, 17]. Some of the mistakes we found on reviewing this online material are mentioned below:

1) No mention of using contralateral hand $[15,17]$

2) No mention of directing spray towards turbinates $[15,17]$.

3) Breath in deeply as you squeeze the bottle. Remove the bottle and sniff once or twice [15].

Turbinate bones in the nose are covered with soft tissue. Directing spray towards the turbinates will allow the medication to work locally on this soft tissue and maximise benefit and at the same time, it will prevent any side effects i.e. nose bleed, irritation [6] associated with the application of the spray on the nasal septum. Hard sniff while administering the spray in the nose can force the drug to go into the oropharynx instead of working locally in the nose.

\subsection{Strengths and limitations of this study:}

Our study was an initial effort towards assessing steroid nasal spray technique and patient compliance in the use of nose spray. Firstly, despite our best efforts to make survey questions clear and straightforward, there is a possibility that some patients may not have understood the survey questions fully. Secondly, this was a single centre study dealing with a small sample of the population in our hospital, hence results of this survey cannot be completely generalised but this study will provide an insight to the clinicians on how prevalent wrong nasal spray technique can be among patients.

\section{Comparison with existing literature:}

Compliance issues identified in our study were associated with both wrong spray dosage and not using the spray regularly. Non-compliance in the use of the nasal spray is a known factor which was been highlighted in the previously published literature [6], [18]. Non- compliance rate found in our study was about $30 \%$. Ganesh et al. reported non-compliance in the nasal spray use in about $29.1 \%$ of patients. Similarly, Nabi et al. investigated the use of steroid nose spray in the patients after sinus surgery and reported non-compliance in $57.4 \%$ of patients.
Asthma control and its correlation with inhaler technique and patient compliance is a well-known association and a plethora of published literature is available [19, 20, 21]. Unfortunately, less literature is available about the nasal spray technique.

\subsection{Implications for Research and practice:}

We recommend for future to design a large-scale multicentre study to assess the spray technique in patients and to investigate the association between disease control and its correlation with nasal spray technique and compliance. Also, we recommend clinicians to educate the patients about spray technique and emphasize the importance of compliance with the nasal spray usage.

\section{Conclusion:}

Wrong spray technique is extremely common among patients using the steroid nose spray. This seems to be overlooked by many clinicians, which is easily correctable. Moreover, patient compliance can be further improved. We emphasize the importance of giving verbal as well as written instructions to the patients when prescribing steroid nose spray.

7. Ethical considerations: This survey was registered with clinical audit registration and management system CARMS- 15756 in Queen Elizabeth Hospital Birmingham, UK.

8. Conflicts of Interest: None declared

9. Data availability statement: The data that support the findings of this study are available from the corresponding author upon reasonable request.

10. Funding: No funding.

\section{References:}

1. Penagos M, Compalati E, Tarantini F, Baena-Cagnani C, Passalacqua G, et.al. (2008). Efficacy of mometasone furoate nasal spray in the treatment of allergic rhinitis. Meta-analysis of randomized, double-blind, placebo-controlled, clinical trials. Allergy; 63(10):1280-1291.

2. Rodrigo G, Neffen H. (2011). Efficacy of fluticasone furoate nasal spray vs. placebo for the treatment of ocular and nasal symptoms of allergic rhinitis: a systematic review. Clin Exp Allergy; 41(2):160-170.

3. Fokkens WJ, Lund VJ, Hopkins C, Hellings PW, Kern R, Reitsma $\mathrm{S}$, et al. European position paper on rhinosinusitis and nasal polyps. Rhinol; 58(29):1-464.

4. National Institute for Health and Care Excellence[internet]. Allergic Rhinitis.

5. Scadding GK, Kariyawasam HH, Scadding G, Mirakian R, Buckley RJ, et al. (2007). BSACI guideline for the diagnosis and management of allergic and non-allergic rhinitis. Clin Exp Allergy; 47(7):856-889.

6. Ganesh V, Banigo A, McMurran A, Shakeel M, Ram B. (2017). Does intranasal steroid spray technique affect side effects and compliance? Results of a patient survey. J Laryngol ;131(11):991996.

7. Bscai improving allergy car.Topical Nasal Steroid Spray; 2017

8. Dymista; 2020

9. Merkus P, Ebbens FA, Muller B, Fokkens WJ. (2006). The 'best method' of topical nasal drug delivery: comparison of seven techniques. Rhinol; 44(2):102-107.

10. Bateman N, Whymark A, Clifton N, Woolford T. (2002). A study of intranasal distribution of azelastine hydrochloride aqueous nasal spray with different spray techniques. Clin Otolaryngol Allied Sci; 27(5):327-330.

11. Tsikoudas A, Homer J. (2008). The delivery of topical nasal sprays and drops to the middle meatus: a semiquantitative analysis. Clin Otolaryngol Allied Sci; 26(4):294-297. 
12. Aggarwal R, Cardozo A, Homer J. (2004). The assessment of topical nasal drug distribution. Clin Otolaryngol Allied Sci; 29(3):201-205.

13. Asthma UK. (2020). How to Use Nasal Spray.

14. American Family Physician. (2000). Nasal Sprays: How to Use Them Correctly.

15. Family doctor.org. (2000). Nasal Sprays: How to Use Them Correctly.

16. Flonase. HOW TO GET COMFORTABLE WITH NASAL SPRAYS (YOUR NOSE WILL THANK YOU)

17. Nasal Sprays: How to Use Them Correctly

18. Nabi S, Rotenberg BW, Vukin I, Payton K, Bureau Y. (2012). Nasal Spray Adherence after Sinus Surgery: Problems and
Predictors. J Otolaryngol Head Neck Surg; (1):S49-55.

19. Baddar S, Jayakrishnan B, Al-Rawas OA. (2014). Asthma control: importance of compliance and inhaler technique assessments. Asthma Res Pract; 51(4):429-434.

20. Hamdan A, Ahmed A, Abdullah A, Khan M, Baharoon S, et al. (2013) Improper inhaler technique is associated with poor asthma control and frequent emergency department visits. Allergy Asthma Clin Immunol; 9(1):8.

21. Kebede B, Mamo G, Molla A. (2019). Association of Asthma Control and Metered-Dose Inhaler Use Technique among Adult Asthmatic Patients Attending Outpatient Clinic, in ResourceLimited Country: A Prospective Study.Allergy Asthma Clin Immunol.

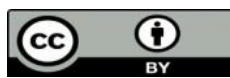

This work is licensed under Creative Commons Attribution 4.0 License

To Submit Your Article Click Here: Submit Manuscript

DOI: $10.31579 / 2692-9562 / 033$
Ready to submit your research? Choose Auctores and benefit from:

* fast, convenient online submission

* rigorous peer review by experienced research in your field

* rapid publication on acceptance

* authors retain copyrights

* unique DOI for all articles

* immediate, unrestricted online access

At Auctores, research is always in progress.

Learn more www.auctoresonline.org/journals/journal-of-clinicalotorhinolaryngology 